\title{
Aetiology and Demographic Attributes of Common Pleural Collections in an African Population
}

\author{
Ezekiel O. Ogunleye, Martins O. Thomas", Olugbenga O. Olusoji \\ Cardiothoracic Surgery Unit, Lagos University Teaching Hospital/College of Medicine of University of Lagos, \\ Idiaraba, Surulere \\ Email: *luwafemithomas@yahoo.com
}

Received March $6^{\text {th }}, 2013$; revised April $8^{\text {th }}, 2013$; accepted April 16 ${ }^{\text {th }}, 2013$

Copyright (C) 2013 Ezekiel O. Ogunleye et al. This is an open access article distributed under the Creative Commons Attribution License, which permits unrestricted use, distribution, and reproduction in any medium, provided the original work is properly cited.

\begin{abstract}
Background: Fluids collect in the pleural space under different conditions and they are of different types. Detailed study of demographic attributes and aetiology of pleural collections has not been well reported in Africa. Aims and Objectives: This study was conducted to determine the demographic attributes and aetiology of common pleural space fluid collections. Methods: The sample population consisted of referrals received via clinics, admission through the emergency centre and wards. We noted their biodata, hospital identification numbers, ages and gender and other relevant parameters. Data analysis was done with special interest in gender-based diseases like ovarian carcinoma prostatic carcinoma and the like. Results: There were 372 patients over a 55-month period. The M:F ratio was 1:1 approximately. The combined mean age was $37.8 \pm 0.92$ years at $95 \%$ confidence interval. Their distribution was negatively skewed and it was leptokurtic. The age bracket of $20-49$ had $65.6 \%$ of cases. There was gender based disparity in ages. Discussion: Malignant effusions constituted majority of sample size and the right side was consistently affected more often than the left side. Conclusion: Advanced malignancies are the commonest causes of pleural effusion. There is ongoing epidemiologic transition of diseases as the burden of non-communicable diseases is now juxtaposed with that of communicable diseases in Africa.
\end{abstract}

Keywords: Pleural; Effusion/Collection; Africa

\section{Introduction}

Fluids often collect within the diseased pleural space. They are either gases or liquids. Causes can be air that leaks from the tracheo-bronchial tree through the lung parenchyma or gases from gas-forming microbials that may infect the pleural cavity or atmospheric air through open chest wounds. Pleural effusion is the most common manifestation of pleural disorders [1]. Pleural effusions affect all ages and sexes. In developing countries, pleural effusion most frequently results as a complication of bacterial pneumonia [1]. Even at that, there are other common causes of pleural collections like malignancies, congestive cardiac failure, connective tissues disorders and trauma among others. There are causes like catamenial effusions and Meigs syndrome which come with some other disease states.

Parapneumonic effusion is defined as pleural effusion associated with lung infection (i.e. pneumonia) [2]. Invasion of pleural fluid by bacteria results in empyema, which is defined as the presence of grossly purulent fluid

*Corresponding author. in the pleural cavity [2].

Between 1962 and 1980, empyema was reported to occur in approximately $0.6 \%$ of children with bacterial pneumonia, despite early diagnosis and treatment [3].

Tuberculous empyema is coming back into prominence because of AIDS pandemic. High HIV burden countries have experienced a high burden of pleural tuberculosis in HIV-infected patients [4]. Within tuberculous empyema group, gender disparity had been reported worldwide, and socio-cultural factors have been proposed as possible causes [5]. The same had been reported in other parapneumonic effusions [6].

Pneumothorax is a common clinical problem. In a study conducted in Italy [7], Surleti and his colleagues found traumatic pneumothorax being associated with blunt chest trauma, pleural effusion, haemothorax, cranial trauma, fractured collar bone, upper and lower limb fractures, pelvic fracture, vertebral and spinal trauma, sternal fracture and abdominal trauma. Within the series, gender distribution of pneumothorax showed 93 males and 9 females and $66.7 \%$ of the cases were spontaneous. In a 
previous multicentre study in Nigeria by Thomas et al. [8], pleural collections in 591 out of 896 patients $(66.0 \%)$ who were admitted over a 10 year period were caused by blunt chest trauma. The inference here is that trauma is the cause of majority of pleural collections in the environment.

Malignant pleural effusions often complicate advanced cancers, like lung cancer, metastatic breast carcinoma and lymphomas [9]. The gender distribution in the quoted study showed 22 males $(62.9 \%)$ and 13 females (37.1\%) (Age range $42-81$ years). In the same study, the main causes of malignant pleural effusions were nonsmall cell lung carcinoma, breast or ovarian cancer and malignant mesothelioma. The main information on gender studies amongst them was that there was no difference in age $(\mathrm{P}=0.88)$ between men $(68.6 \pm 11.6$ years $)$ and women ( $68.0 \pm 8.7$ years).

In a previous study in Nigeria [10], Thomas et al. published their series on the use of tetracycline suspension for pleurodesis in 129 patients who had malignant pleural effusions. There they found a gender ratio (M:F) of 1:4.9 in the distribution. In the same series, majority of malignant pleural effusions were caused by breast carcinoma (106 out of 129).

From the foregoing, detailed study of demographic attributes, and etiologies of pleural collection have not been well reported. This justifies the need for our study which was designed to bring up these essential components of knowledge of pleural space collections.

\section{Methodology}

The sample population was recruited through referrals to our clinics, admission through the emergency centre and wards of Lagos University Teaching Hospital over the study period.

A proforma was designed to accommodate data on all patients who had pleural collections. We noted their biodata, hospital identification number and their ages and gender. Diagnosis of pleural collection was made from clinical examination (including diagnostic thoracentesis where indicated), chest radiologic studies including plain chest radiographs or computerized tomographic scans or both as may be affordable and appropriate. The affected sides and causes of pleural collection were noted for each patient. Physical, cytological and biochemical evaluation of collections were done to characterize effusions when no clear-cut categorization could be achieved.

All post-thoracotomy patients were excluded because they were expected to have some collections post-operatively.

The data so collected were entered into SPSS 17 and they were analysed. Their gender distribution was studied in detail to determine its relationship with the causes of pleural collection, the affected sides and differential age and sex distribution.

The ages were also studied against the primary diagnoses (causes of collection) and the types of pleural collection were noted.

We applied various statistical modules to investigate all variables in relation to the derivable statistic as stated under results.

The derived information formed the contents of the results as stated (vide infra). The results were then applied for discussion and suggestions on the way forward.

\section{Results}

In a 55-month period, $372(\mathrm{n}=372)$ patients had pleural collections from different causes. There were 182 males (48.9\%) and 190 females (51.1\%). These averaged about 7 patients per month. In all, 409 closed tube thoracostomy drainages (CTTD) were done for the 372 patients because some occurred bilaterally.

\subsection{Age and Gender Distribution}

The sample had a M:F ratio of 1:1 approximately with the female group dominating by a very narrow margin ( $48.9 \%$ for males $51.1 \%$ for females).

The combined mean age was $37.8 \pm 0.92$ years at $95 \%$ confidence level. The median age was 37.9 years while the mode was 26.0 years. The standard deviation was 17.72 years. The distribution had a negative skewness of 0.066 (std error of skewness -0.126 ) and it is leptokurtic (std error of kurtosis 0.007).

The minimum age was 0.3 years while the maximum was 87 years (a range of 86.7 years). The $50^{\text {th }}$ percentile was 37.9 years. The mean, median and $50^{\text {th }}$ percentile are very close, therefore it is a normal distribution.

Majority of cases (65.6\%) occurred among the 20 - 49 years age bracket. The paediatric group accounted for $0.1 \%$.

Differential analysis showed some disparity in genderbased ages. The mean for males was $34.6 \pm 1.66$ (females had a mean of $41.2 \pm 2.11$ years). The median for males was 32.0 ears while that of the females was 42 years-all at $95 \%$ confidence interval. The standard deviation was 14.51 for males and 18.06 for females. The age range for males was 71.2 years and 84.4 years for the females. Incidentally, the distribution was positively skewed for males while it was negatively skewed for the females. Both sexes were leptokurtic.

Test of normality showed more compliance within the male group (Kolmogorov-Smirnor test with Lilliefors significance correction).

The female group did not measure up adequately (sig was 0.200 at $73 \mathrm{df}$ ) using above method.

Overall Pearson Chi-square analysis showed a signifi- 
cant value of 3227.63 (at $2812 \mathrm{df}$ ) with a likelihood ratio of compliance at a high level of 895.77 (df 2812). Test of dependence using Goodman and Kruskaltau test showed significant dependence of diagnosis on age of presentation. The uncertainty coefficient was generally low in all age groups when related with the cause of pleural collection.

The age and gender analysis is illustrated in Table $\mathbf{1 .}$

The male and female distributions are presented in histograms (Figures $1 \& 2$ respectively). Age distribution of the series is depicted by Figure 3.

\subsection{Causes and Types of Pleural Collections}

\subsubsection{Primary Diseases}

Malignant causes of pleural collection accounted for 212 $(57.0 \%)$ of all cases. Within this group, breast carcinoma constituted $46.7 \%$ of the malignant cases and $26.6 \%$ of all indications for chest tube insertion for evacuation of pleural collections. This is followed by bronchogenic and ovarian carcinomas which were 20 and 10 cases respectively. The non-malignant indications were $160(\mathrm{n}=160)$.

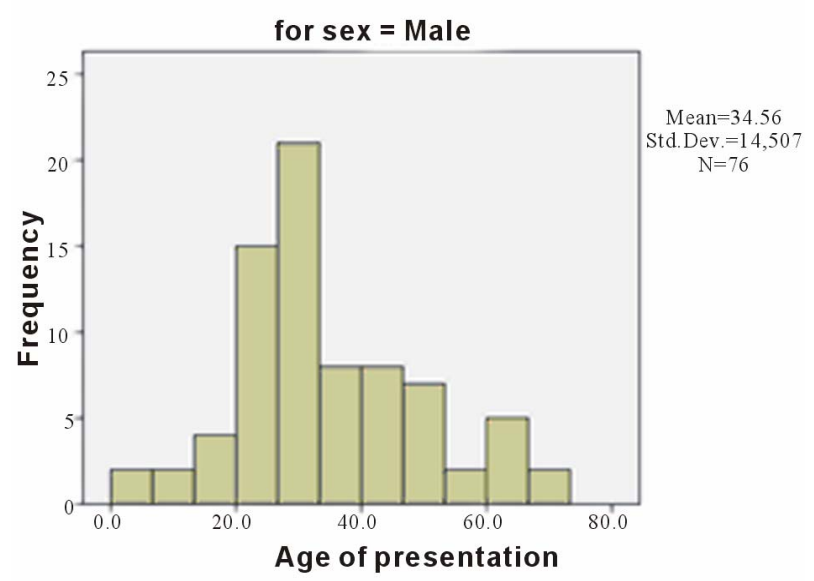

Figure 1. Showing differential age distribution for males.
This constituted $43.0 \%$ of all indications. Within the group, trauma accounted for $58.8 \%$ of non-malignant intra-pleural collections and $25.3 \%$ of all indications for chest tube insertion.

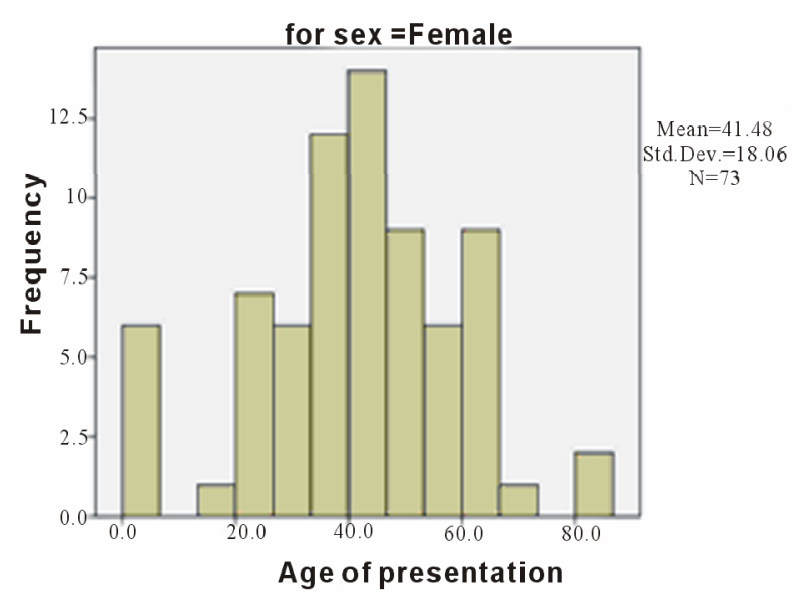

Figure 2. Showing differential age distribution for females.

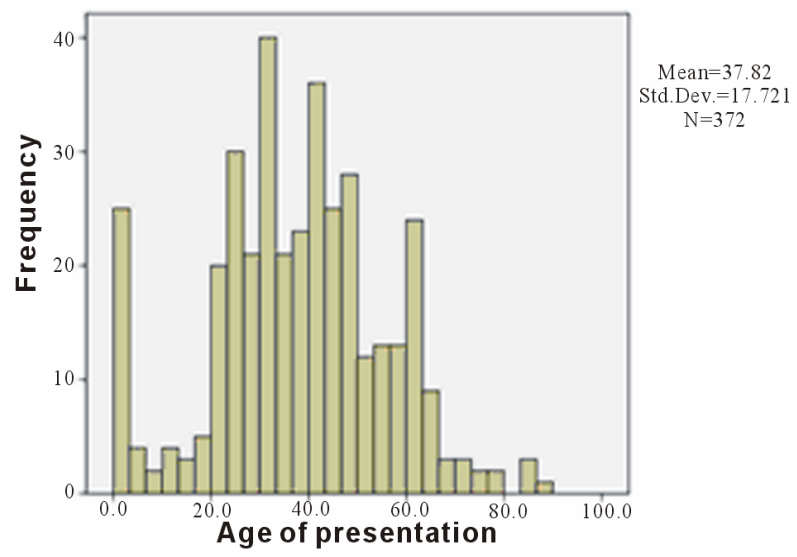

Figure 3. Showing combined age distribution at presentation.

Table 1. Age and sex analysis of the patients.

\begin{tabular}{|c|c|c|c|c|c|c|}
\hline Causes & Males & Females & Mean Age (yrs) & Age (Min) Years & Age (Max) Years & Age Range \\
\hline Breast Carcinoma & 2 & 97 & $45.5 \pm 1.2$ & 23.0 & 85 & 62.0 \\
\hline Bronchogenic carcinoma & 11 & 9 & $59.5 \pm 2.2$ & 34.0 & 75 & 41.0 \\
\hline Lymphoma & 4 & 2 & $46.3 \pm 9.0$ & 25.0 & 87 & 62.0 \\
\hline Hepatoma & 1 & 1 & $44.0 \pm 11$ & 33.0 & 55 & 22.0 \\
\hline Prostatic carcinoma & 4 & - & $62.5 \pm 6.6$ & 47.0 & 79 & 32.0 \\
\hline Bronchopneumonia & 12 & 10 & $1.9 \pm 0.4$ & 0.3 & 9 & 8.7 \\
\hline Pulmonary tuberculosis & 42 & 16 & $36.9 \pm .8$ & 13.0 & 72 & 59.0 \\
\hline Trauma & 74 & 20 & $33.9 \pm 1.2$ & 4.0 & 63 & 59.0 \\
\hline
\end{tabular}


Pulmonary tuberculosis constituted $38.1 \%(n=61)$ of non-malignant causes and $16.4 \%$ of all indications for chest tube insertion.

Within the non-malignant group para-pneumonic effusions were 35 cases $(21.9 \%$ of non-malignant and $9.4 \%$ of all cases). Amoebiasis and endometriosis caused effusion in one patient each within the series. The diagnosis of primary disease at presentation is in Figures 4 and 5.

\subsubsection{Types of Pleural Collection}

Malignant effusions occurred either as haemorrhagic or non haemorrhagic effusions in 212 patients within the study period. Empyema thoracis (acute or sub-acute types only) constituted $73.1 \%(n=117)$ of the non-malignant cases and $31.5 \%$ of all indications. There were 2 cases of chylothorax in the sample - one each caused by lymphoma and trauma. A bulk of the trauma cases $(55.3 \%)$ presented as frank haemothoraces while 25 cases $(26.6 \%)$ and 17 cases $(18.1 \%)$ presented as haemopneumothoraces and pneumothoraces respectively. There were 16 transudates and $81.3 \%$ of them were due to congestive cardiac failure. There was a case of Meigs syndrome. The relative distribution of types of effusion is represented in Figure 6.

\subsubsection{Sides Affected by Pleural Collection}

Cumulatively, the right side alone was affected in $56.7 \%$ $(\mathrm{n}=211)$ of cases while the left side alone was affected in $33.3 \%$ of cases $(n=124)$. Bilateral collections occurred in 37 cases $(9.9 \%)$.

Figure 6 shows the gender relationship of affected sides. There was predilection for right side in both sexes.
Males had 59.3\% in the right chest, 33.5\% in the left and $7.1 \%$ occurred bilaterally. Right to left ratio (R:L) was 1.6:1. The females had $54.2 \%$ on the right, $33.2 \%$ on the left and it was bilateral in $12.6 \%$ cases with a $\mathrm{R}: \mathrm{L}$ ratio of 1.5:1.

Malignant effusions occurred in the right side in $58.1 \%$ of cases and they occurred on the left side in $29.4 \%$ of cases. Bilaterality was $12.5 \%$. The overall right to left ratio (R:L) was 1.7:1 for malignant effusions.

Most empyema thoracis (72.8\%) occurred in the right. In the same vein, $22.2 \%$ of them occurred on the left while bilateral cases were $4.9 \%$. Therefore R:L for empyema was 2.9:1. Trauma had a right side preponderance of $53.2 \%$, left preponderance of $39.4 \%$ and bilaterality of $7.4 \%$. The R:L ratio was 1.3:1. A bar chart of gender and affected side is depicted by Figure 7.

\section{Discussion}

Pleural space fluid collections can be caused by malignant and non-malignant and diseases and they affect all ages and gender in varying proportion worldwide. Lunachi et al. [9] working in Italy had 35 patients who underwent video assisted thoracoscopic (VATS) talc pleurodesis. In their series, there were 22 males $(62.9 \%)$ and 13 females $(37.1 \%)$ giving a $\mathrm{M}: \mathrm{F}$ ratio of $1.7: 1$. A direct reversal of this ratio was recorded by Adewuyi and his colleagues [11] in Zaria, Northern Nigeria where they studied the chest radiographs of advanced cancer cases.

In our series, there were 182 males and 190 females. More striking gender disparities were found with different causes of effusion. In our series, the M:F ratio for

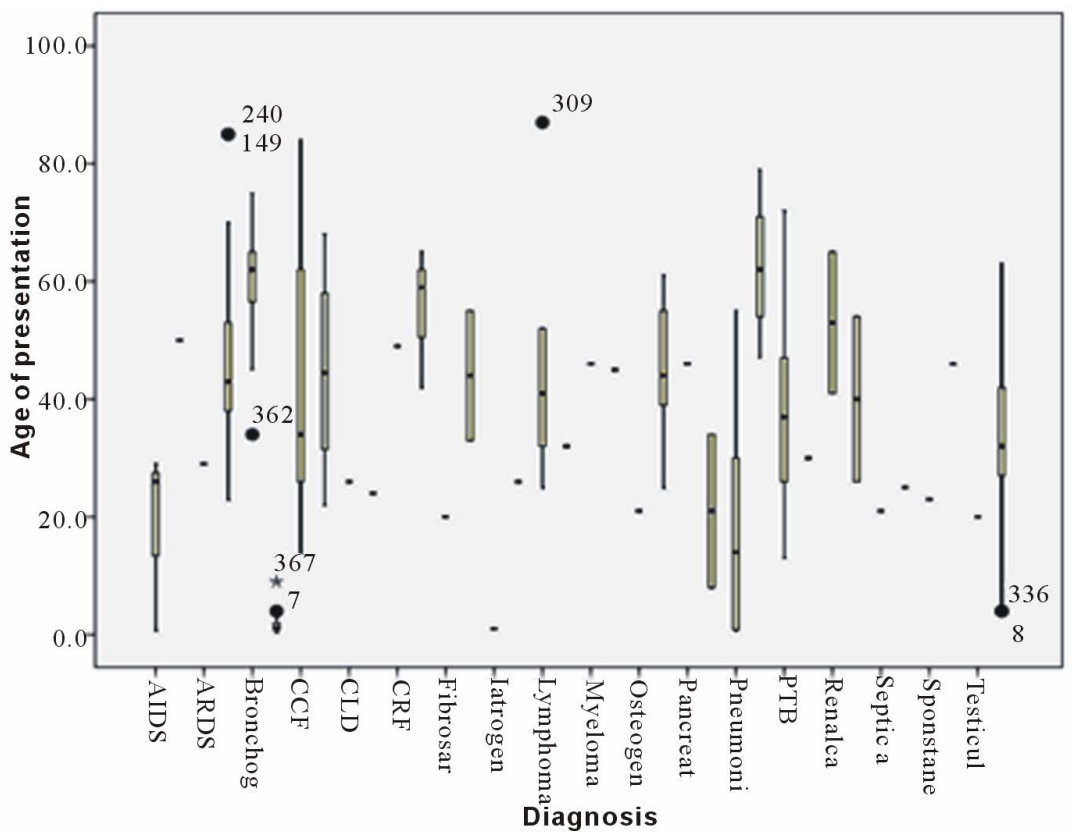

Figure 4. Stem and plot distribution of diagnosis at age of presentation. 


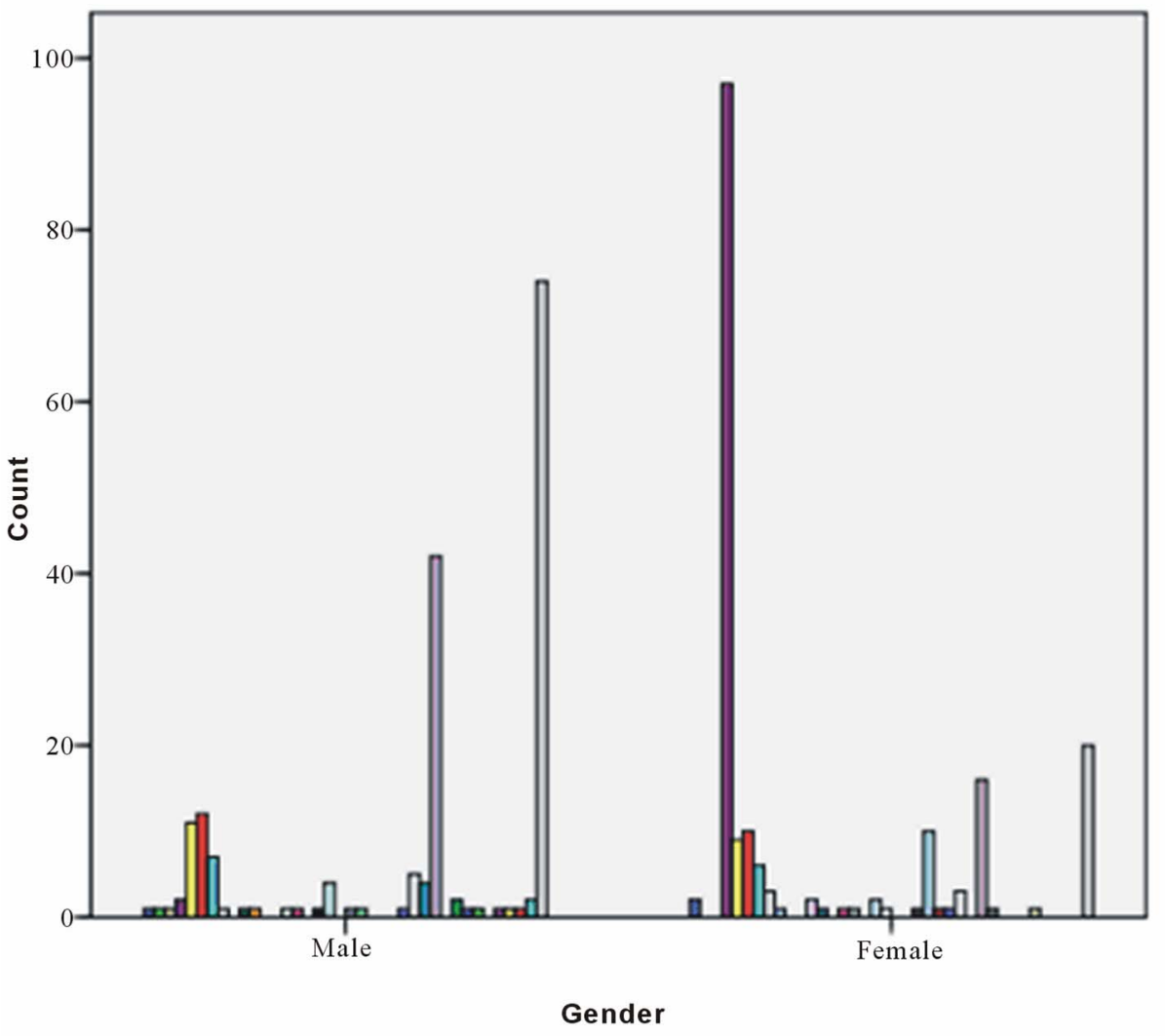

\section{AIDS}

Amocbiasis

ARDS

Breast Ca

Bronchogenic $\mathrm{Ca}$

Bronchopneurnonia

CCF

Cervical Ca

CLD

Colonic $\mathrm{Ca}$

CRF

EEndorncdrial Ca

Endorncdriasis

Fibrasarcarna

Hepadorna

Ladrogenic

Lipaid Pneurnaria

Lyrnpharna

Meig Sydrnarne

Myelarna

Oesaphagesal rupture

Osteogenic Sarcarna

Orarian $\mathrm{Ca}$

Pancreantc $\mathrm{Ca}$

Peritanis

$\square$ Pneurnoria

Prostatic Ca

PTB

Puerperal sepsis

Renal Ca

saroorna

Saroorna Cheast wall

Septic abortion

Salt Tissue sarcarna

Sponbanopus

Subphranic absccess

Figure 5. Showing gender distribution of the causes of effusion.

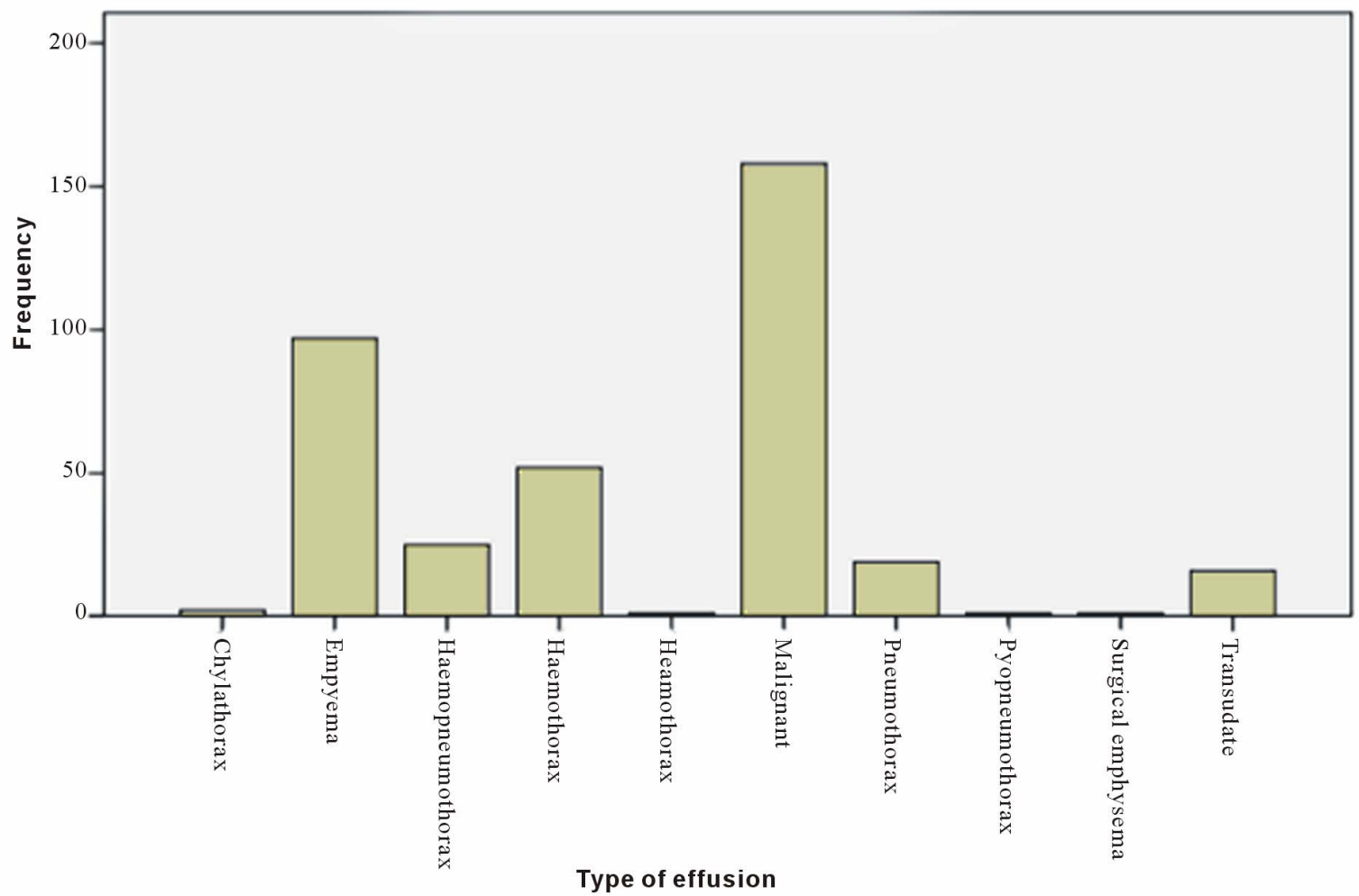

Figure 6. Showing the relative preponderance of types of effusion. 


\section{Bar Chart}

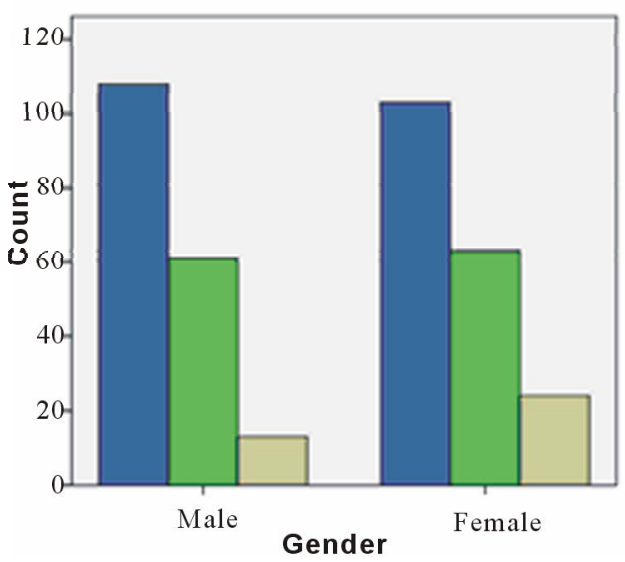

Figure 7. Showing effect of gender on affected side.

breast carcinoma patients who had effusions was 1:49 and that for bronchogenic carcinoma was 1.2:1. In view of the overwhelming preponderance of breast carcinoma in absolute number and proportion, it is clear that malignant pleural effusions are generally commoner in females and they are overwhelmingly caused by breast carcinoma.

The combined mean age of the patients in our series was $37.8 \pm 0.92$. There was notable gender based disparity in the mean ages amongst them. At 95\% confidence interval, the mean age for females was higher (41.2 \pm 2.11 years for females and $34.6 \pm 1.66$ years the males).

The mean age for having malignant effusions due to breast carcinoma was $45.5 \pm 1.24$ years at $95 \%$ confidence interval. In the same vein, bronchogenic carcinoma occurs at a mean age of $59.5 \pm 2.164$. The implication of this is that malignant pleural effusions occur at younger ages in breast cancer than bronchogenic carcinoma. This position is at variance with the situation in Italy [9] where non small cell lung carcinoma is the leading cause of malignant pleural effusion. In the same series, there was no gender-based age disparity. Earlier studies in Nigeria $[10,11]$ are consistent with the current trend in that, malignant breast diseases constitute a leading cause of effusions in this part of the world.

Parapneumonic effusions caused by bronchopneumonia occurred at very young ages in this study. The mean age of affected patients was $1.9 \pm 0.40$ years. This contrasts with those caused by pulmonary tuberculosis where the mean age was $36.9 \pm 1.80$ years.

In this study, we found that the mean ages of $33.9 \pm$ 1.20 years for trauma cases is very close to those of pulmonary tuberculosis and malignant effusions (in males). It was also found that effusions of infective origin were commoner in males. This is very similar to the situation in Pakistan by Ayub and his colleagues [12] and Zablockis in Lithuania [13] who found that empyema tho- racis commonly affects males.

In Nepal [14], Dhital and his colleagues found that the commonest cause of unilateral pleural effusion is tuberculosis followed by parapneumonic effusions and most of these cases occurred at younger ages of 21 - 30 years.

In our study, unilateral occurrence of pleural collection on the right was found in $56.7 \%$ of cases. The left side alone was affected in $33.3 \%$ and bilateral occurrence was found in $9.9 \%$. When these were pooled together, there was right dominance in both genders. The situation was maintained with malignant effusions, empyema thoracis and in pleural collections caused by trauma.

\section{Conclusions}

Our conclusions were that pleural collections generally affect the right side more than the left but no clear reason could be ascribed to this finding.

We also concluded that advanced malignancies are the commonest causes of symptomatic pleural effusions and that within the group breast carcinoma exerts much weight over and above other malignancies.

This further strengthens the theory of epidemiologic transmission of diseases in Africa as previously demonstrated by Thomas et al. [15] in their study of cardiacrelated deaths in an African population. This indeed means that the burden of non-communicable diseases is now being juxtaposed with that of communicable diseases in Africa.

The overall effect of it is that African countries need to double efforts in disease burden reduction activities to stem the tide.

\section{REFERENCES}

[1] H. T. Mocelin and G. B. Fischer, "Epidemiology, Presentation and Treatment of Pleural Effusion," Paediatric Respiratory Reviews, Vol. 3, No. 4, 2002, pp. 292-297. doi:10.1016/S1526-0542(02)00269-5

[2] A. J. Ibrahim, R. Gregory, F. Khoulood and L. K. Sheldon, "Epidemiology, Clinical Presentation and Evaluation of Parapneumonic Effusion and Empyema in Children," 2013, in press.

[3] T. Chonmaitree and K. R. Powell, "Parapneumonic Pleural Effusion and Empyema in Children. Review of a 19 Year Experience, 1962-1980," Clinical Pediatrics (Philadelphia), Vol. 22, No. 6, 1983, pp. 414-419.

[4] A. Aljohaney, K. Amjadi and G. G. Alvarez, "A Systematic Review of the Epidemiology, Immunopathogenesis, Diagnosis and Treatment of Pleural Tuberculosis in HIVInfected Patients," Clinical and Developmental Immunology, Vol. 2012, 2012, Article ID: 842045.

[5] J. Y. Feng, S F. Huang, W. Y. Ting, Y. C. Chen, Y. Y. Lin, R. M. Huang, C. H. Lin, J. J. Hwang, J. J. Lee, M. C. Yu, K. W. Yu, Y. C. Lee and W. J. Su. "Gender Differ- 
ences in Treatment Outcomes of Tuberculosis Patients in Taiwan: A Prospective Observational Study," Clinical Microbiology and Infection, Vol. 18, No. 9, 2012, pp. 331-337. doi:10.1111/j.1469-0691.2012.03931.x

[6] M. I. Muhammad, "Management of Complicated Parapneumonic Effusion and Empyema Using Different Treatment Modalities," Asian Cardiovascular and Thoracic Annals, Vol. 20, No. 2, 2012, pp. 177-181. doi: $10.1177 / 0218492311435338$

[7] S. Surleti, F. Fama, L. M. Murabito, S. A. Villari, C. C. Bramantiand M. A. G. Florio, "Pneumothorax in the Emergency Room: Personal Caseload," Giornale di Chirurgia, Vol. 32, No. 11-12, 2011, pp. 473-478.

[8] M. O. Thomas and E. O. Ogunleye, "Aetiology and Management Challenges of Blunt Chest Trauma in Nigeria," Asian Cardiovascular and Thoracic Annals, Vol. 17, No. 6, 2009, pp. 608-611. doi:10.1177/0218492309349069

[9] F. Lumachi, F. Mazza, M. Ermani, G. B. Chiara and S. M. Basso, "Talc Pleurodesis as Surgical Palliation of Patients with Malignant Pleural Effusion. Analysis of Factor Affecting Survival," Anticancer Research, Vol. 32, No. 11, 2012, pp. 5071-5074.

[10] M. O. Thomas, O. A. Atoyebi, C. E. Atimomo and E. O. Ogunleye, "Efficacy of Tetracycline Suspension for Pleurodesis," Nigeria Journal Surgery, Vol. 11, No. 1, 2005, pp. 14-16.

[11] S. A. Adewuyi, R. Arogundada, J. B. Igashi, N. D. Chom, A. U. Hamidu and O. B. Campbell, "The Pattern of Chest Radiographic Findings in Metastatic Cancer Patients Seen in a Tertiary Hospital in Northern Nigeria," Nigerian Postgraduate Medical Journal, Vol. 18, No. 4, 2011, pp. 245-250.

[12] S. Ghaffar, I. A. Khan, S. Asif and Z. Rahman, "Empyema Thoracis: Management Outcome," Journal of Ayub Medical College, Abbottabad, Vol. 22, No. 3, 2010, pp. 12-14.

[13] R. Zablockis, R. Petruskeviciene and R. V. Nargela, "Causes and Risk Factors of Pleural Empyema and Complicated Parapneumonic Pleural Effusion," Medicina (Kaunas), Vol. 46, No. 2, 2010, pp. 113-119.

[14] K. R. Dhital, R. Acharya, R. Bhandari, P. Kharel, K. P. Giri and R.Tamralear, "Clinical Profile of Patients with Pleural Effusion Admitted to KMCTH," Kathmandu University Medical Journal (KUMJ), Vol. 7, No. 28, 2009, pp. 438-444.

[15] M. O. Thomas, N. A. Awolola and O. O. Olusoji, "Adult Cardiac-Related Deaths: A Reflection of Epidemiologic Transition of Diseases in the Developing World?" World Journal of Cardiovascular Surgery, Vol. 2, No. 4, 2012, pp. 108-113. 